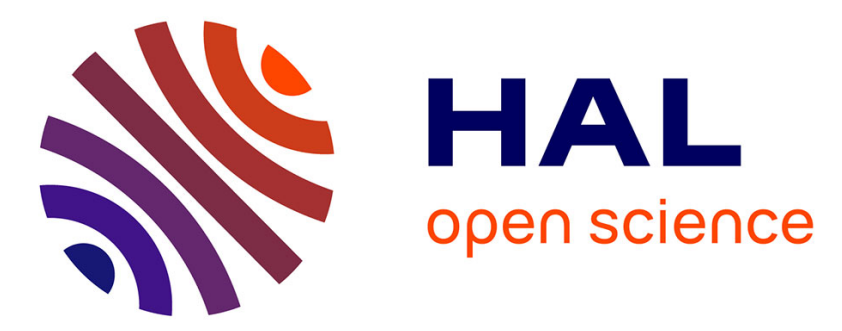

\title{
Hyperthermic intraperitoneal chemotherapy (HIPEC): Should we look closer at the microenvironment?
} Adrien Crestani, Louise Benoit, Cyril Touboul, Jennifer Pasquier

\section{To cite this version:}

Adrien Crestani, Louise Benoit, Cyril Touboul, Jennifer Pasquier. Hyperthermic intraperitoneal chemotherapy (HIPEC): Should we look closer at the microenvironment?. Gynecologic Oncology, 2020, 179 (1), pp.285-294. hal-03023263

\section{HAL Id: hal-03023263 \\ https://hal.sorbonne-universite.fr/hal-03023263}

Submitted on 25 Nov 2020

HAL is a multi-disciplinary open access archive for the deposit and dissemination of scientific research documents, whether they are published or not. The documents may come from teaching and research institutions in France or abroad, or from public or private research centers.
L'archive ouverte pluridisciplinaire HAL, est destinée au dépôt et à la diffusion de documents scientifiques de niveau recherche, publiés ou non, émanant des établissements d'enseignement et de recherche français ou étrangers, des laboratoires publics ou privés. 

HIPEC has an impact on the whole tumour microenvironment.

23 HIPEC has both negative and positive effect on tumor environment and its anti-tumoral activity.

\section{microenvironment?}

Adrien CRESTANI ${ }^{1,2^{*}}$, Louise BENOIT ${ }^{1,2^{*}}$, Cyril TOUBOUL ${ }^{1,2}$, Jennifer PASQUIER ${ }^{1,3}$

1. INSERM UMRS 938, Centre de recherche Saint Antoine, Team Cancer Biology and Therapeutics, Institut Universitaire de Cancérologie, Sorbonne Université, F-75012 Paris, France.

2. Service de chirurgie gynécologique, hôpital Tenon, 4, rue de la Chine, 75012 Paris, France.

3. Department of Genetic Medicine, Weill Cornell Medicine - Qatar.

*These authors contributed equally to the work

Corresponding author:

Adrien CRESTANI

adriencrestani@hotmail.fr

Hôpital Tenon, 4, rue de la Chine, 75012 Paris, France.

$+33660643911$

HIGHLIGHTS:

There is no consensus on hyperthermic intraperitoneal chemotherapy (HIPEC) modalities. 


\section{ABSTRACT}

The age of cancer as an isolated single-cell concept is now behind us. It is now established that epithelial ovarian cancer, like other cancers, interacts with the healthy bystander cells to influence them and takes advantage of their nutritional, immunological, disseminating and other capacities. This interaction has become a therapeutic target, as shown by the numerous studies on this subject. Intraperitoneal chemo-hyperthermia has been part of the therapeutic armamentarium for some time yet its efficiency in ovarian cancer has only been recently proven in a randomized controlled trial. However, its therapeutic performance is not revolutionary and epithelial ovarian cancer maintains a high mortality. In this review, we studied the impact of HIPEC on the microenvironment and vice versa to determine whether it could be the key to this lukewarm efficacy. We began by exploring the modalities of HIPEC and establishing the reasons that make this treatment topical. Then, we examined its impact on each element of the tumour environment to obtain a global view of the resistance mechanisms at work in HIPEC.

Keywords: Ovarian cancer / Hyperthermic intra peritoneal chemotherapy/ Survival / Microenvironment / Resistance

1

\section{I- Introduction}

Hyperthermic intra peritoneal chemotherapy (HIPEC) is a treatment option for patient with abdominal cancer and peritoneal carcinosis, without distant metastasis. It is a combination of three procedures: intra peritoneal drug release, chemotherapy and hyperthermia. It has mainly been evaluated in peritoneal carcinomatosis in colorectal, mucinous appendicular adenocarninoma and ovarian cancer. In the latter, its benefits in terms of overall survival and recurrence-free survival have been showed by van Driel et al. [1] in the first prospective randomized controlled trial, in 2018. Unfortunately, the survival length remains short with a median recurrence free survival of 14.2 months in stage 3 patients with ovarian cancer 
undergoing total cytoreductive surgery and HIPEC [2]. There must be an underlying mechanism explaining the resistance of cancer cells to HIPEC.

It has been demonstrated that the tumor cells strongly interact with their microenvironment

[3]. Tumoral colonization and proliferation are subject to the permissiveness of the microenvironment of the targeted organ. As a result, the interaction between disseminated malignant tumor cells and their microenvironment is a key mechanism in their progression and metastasis. The tumor microenvironment (TME) is defined as the cellular and molecular components and the mechanical stresses that surround the tumor cells and interact with them [4]. The cellular component of the TME includes for instance stromal cells such as fibroblasts, cells of the immune system and vascular cells. Recently, few studies reported an influence of TME cells on the sensitivity of cancer cells to hyperthermia [5]. Here, we aimed to review the possible role of the TME in the resistance to HIPEC.

(1)

\section{II- From hyperthermia to HIPEC}

\section{Hyperthermia}

Hyperthermia therapy is defined by the rising of the human temperature over $38^{\circ} \mathrm{C}$. Hyperthermia over $43^{\circ}$ was found to have a direct cytotoxic effect in vitro in animals[6]. Each cell has a different sensitivity to hyperthermia yet there seems to be a clear thermic threshold. Over $43^{\circ} \mathrm{C}$, an exponential cell death occurs. The time needed to obtain this cell death, is correlated to the temperature used. When diminishing the temperature of one degree Celsius, the exposure time must be multiplied by two between $42.5^{\circ} \mathrm{C}$ and $47^{\circ} \mathrm{C}$ [7] . There is actually no consensus on the time of exposure and the temperature. In the recent trial by van Driel's team [1], an intraabdominal temperature of $40^{\circ} \mathrm{C}\left(104^{\circ} \mathrm{F}\right)$ was maintained by circulation of the heated saline during 90 minutes whereas in Lee et al. study [8] they used a dextrose solution $1.5 \%$ at $42^{\circ} \mathrm{C}$ for 90 minutes. 
Hyperthermia is all about dose. In vivo, in a healthy tissue, hyperthermia will increase

tissue oxygenation by raising blood flow through decreasing peripheral vascular resistance by mechanical dilation via the smooth muscle cells that cover the microveins [9]. When the temperature exceeds this threshold, on the contrary, the blood flow decreases via fluid shift between interstitial compartments micro-thrombosis and endothelial swelling, resulting in decreased tissue oxygenation and therefore cell death. Damages caused by moderate hyperthermia depends on the type of tissue [10]. Nevertheless, in tumoral tissue, vascular architecture is complex and anarchic with territories in constitutive hypoxia, de facto increasing the sensitivity of the tissue to hyperthermia.

Thus in oncology, whole-body hyperthermia at temperatures over $41.5^{\circ} \mathrm{C}$ combined with chemotherapy for metastatic cancers is also gradually finding its place in oncology [11].

\section{Intraperitoneal Chemotherapy}

As ovarian carcinoma is essentially a peritoneal disease, intraperitoneal delivery of chemotherapy enhances drug delivery at the peritoneal surface with theoretical low systemic passage and may improve outcomes. Thus, chemotherapy can be delivered directly through the peritoneum. A Cochrane’s meta-analysis included 2119 women and 9 randomized studies comparing intravenous (IV) and intraperitoneal (IP) administration of adjuvant chemotherapy. Intraperitoneal chemotherapy provides a significant gain in overall survival (OS) (8 studies), with a hazard ratio (HR) of 0.81 (95\% CI 0.72-0.90). This gain in OS is independent of the number of drugs used or the dose.

The phase III randomized trial of intraperitoneal chemotherapy in ovarian cancer from 2006 [12] compared paclitaxel $135 \mathrm{mg} / \mathrm{m}^{2} / 24 \mathrm{~h}$ on day one (D1) and cisplatin $75 \mathrm{mg} / \mathrm{m}^{2} \mathrm{IV}$ on D1 to paclitaxel $135 \mathrm{mg} / \mathrm{m}^{2} / 24 \mathrm{~h}$ IV on D1, cisplatin $100 \mathrm{mg} / \mathrm{m}^{2}$ IP on D2 and paclitaxel $60 \mathrm{mg} / \mathrm{m}^{2} \mathrm{IP}$ on D8. Median progression free survival (PFS) was better in the intra-peritoneal (IP) group but 
with elevated impact on the quality of life mainly related to the presence of the peritoneal catheter. Many studies have searched for new protocols to increase the tolerance of the peritoneal approach $[13,14]$ mainly by lowering IP Cisplatin doses. Yet, despite these data, IPC has not been accepted as a standard treatment. In order to reduce this toxicity and retain the efficacy, the gynecology oncology group (GOG) designed the GOG-252[15], a randomized controlled trial comparing totally IV route chemotherapy, the former standard treatment with IP Cisplatin and IP Paclitaxel and a third new arm supposed to reduce IP toxicity with IP Carboplatin and IV Paclitaxel; each arm receiving additional treatment with Bevacizumab. No difference in PFS or OS was found. Nevertheless, the authors suggested that Bevacizumab may have compromised the efficacy of the Cisplatin IP arm. Though, considering these data, IP route has little support from the scientific community.

\section{Intraoperative intraperitoneal chemotherapy with hyperthermia - HIPEC.}

The pharmacokinetic advantage of intraperitoneal chemotherapy is the most important rational for HIPEC in peritoneal surface malignancy. The objective of intraoperative exposure of the peritoneal cavity is to free itself from possible digestive adhesions that could exclude certain territories and increase toxicity. Furthermore, extended resections of the peritoneum and or organs covered by peritoneum do not modify HIPEC pharmacodynamics [16]. Penetration of chemotherapy agents are ideally measured by the area under curve (AUC) which is an integral of concentration over time. An AUC ratio of intraperitoneal concentration to plasma concentration time reflects how much of the drug is preserved in the peritoneal cavity and how much was absorbed by the systemic circulation, the objective is therefore a high AUC ratio.

The agent has to be of large molecular weight and water-soluble, rapidly cleared from the systemic circulation, potentiated by hyperthermia, and must have proven its efficacy in ovarian cancer. Platinum salts have been mainly explored in HIPEC. They have in common the 
126 chemotherapy, recommended as a neoadjuvant agent combined with paclitaxel. Its advantage 127 over other platinum agents in intraperitoneal administration is its higher molecular weight and

128 lower renal toxicity. Still it suffers from a low peritoneal to plasma AUC around 15-20 [18], 129 and therefore, 7 times more platinum could be detected after Cisplatin treatment than after 130 equimolar treatment with carboplatin [19] both in cultured cells in vitro and in peritoneal tumors 131 in vivo. This is mainly because of the high liposolubility of Cisplatin resulting in an

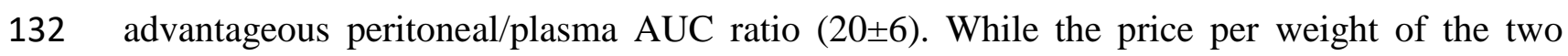
133 molecules is the same, administered doses of Cisplatin varies from 50 to $120 \mathrm{mg} / \mathrm{m}^{2}$ 134 respectively 300 to $1,000 \mathrm{mg} / \mathrm{m}^{2}$ for Carboplatin. However, pharmacokinetic studies favor the 135 use of Carboplatin because its peritoneal clearance is 3 times lower, thus explaining perhaps its 136 better tolerance in IPC. Washing the peritoneal cavity at the end of the procedure frees us from 137 this difference. In the phase 3 randomized OVHIPEC trial by van Driel et al. [1] which provides 138 the basis for the most recent recommendations of gynecological societies; surgery followed 3 139 IV chemotherapy treatments (carboplatin AUC 6 and paclitaxel $175 \mathrm{mg} / \mathrm{m}^{2}$ ) and the 140 experimental arm consisted in surgery plus HIPEC (Cisplatin $100 \mathrm{mg} / \mathrm{m}^{2}$ at $40^{\circ} \mathrm{C}$ delivered in 141 three doses with nephroprotection by thiosulfate).

142 In addition to the extreme variability of the drugs and temperatures used, there is no 143 consensus on the HIPEC technique. In a recent review of the current practice in Spanish 144 hospitals [20], 65\% of the centers administered HIPEC using a closed system, as opposed to 145 the open system used for example in the Van Driel study, were the debulked cavity is left 146 open. 53\% of the surgeons indicated that the infusion temperature of the intraperitoneal 147 chemotherapy solution(s) was $42{ }^{\circ} \mathrm{C}$. Median time of exposure was 90 minutes. The cost it 148 takes to perform HIPEC, excluding the price of running the machine and chemotherapy 
149

150

151

152

153

154

155

156

157

158

159

160

161

162

163

164

165

166

167

168

169

170

171

172

173

agents, was mainly above $\$ 4000$. Figure 1 is a schematic representation of an open coliseum HIPEC identical to that used in the Van Driel trial [1].

Figure 1 : HIPEC open technique : Coliseum.

Although HIPEC has been used in peritoneal carcinosis for more than 30 years, its use is struggling to find its place. In ovarian cancer, even if the Van Driel trial is a major argument in the decision to offer this therapy to patients, it seems that there is no unanimity, mainly because the gain in survival remains moderate.

It now seems fundamental to reflect on the mechanisms of resistance that could explain this phenomenon, and direct us towards future directions of therapeutic potentiation.

Table 1: HIPEC trials through the last 10 years.

\section{III- Role of the microenvironment in HIPEC}

The ovarian tumor microenvironment consists of structural extracellular matrix (ECM) and cellular network. The latter can be divided in endogenous or recruited immune cells, supportive stromal cells such as fibroblasts, endothelial cells and adipose tissue[4]. It has been shown that cancer promotes an inflammatory microenvironment [21]. Chronic inflammation, caused by the proliferation of tumor cells, leads to a paradoxical reaction of the microenvironment that will lead to the proliferation of cancer cells. The aim of this literature review is to describe the interactions of the microenvironment with cancer cells during HIPEC.

Figure 2: Biocellular mechanisms at work in the ovarian tumor microenvironment during HIPEC.

\section{Role of the extracellular matrix}

Non-cellular components of the tumour microenvironment are composed of the ECM, ECM remodelling enzymes and growth factors. ECM is a specific component of the tumour 
microenvironment that plays a role in cell attachment, survival, communication, spreading,

175 migration, proliferation and multicellular organisation by a complex mix of architectural,

176 mechanical and biochemical signals [22]. Components of the ECM are called the matrisome,

177 and are grouped into two families: proteoglycans and fibrous proteins [23]. Peptides structures

178 and activities are inherently thermolabile, thermodynamic considerations drive the assembly of

179 these structures (e.g. hydrogen bonding, electrostatic interactions, van der Waals interactions,

180 and the hydrophobic effect) and most proteins are therefore temperature sensitive.

181 Collagen I is one of the main component of the fibrous proteins. Hepatocellular cancer cells 182 (HCC), exposed to a sublethal hyperthermia, and then cultured with collagen I showed 183 accelerated migration and highest invasive profile [24]. Heat shock protein (HSP) 47 is a 184 chaperone of collagen I and its precursors and form a complex in the endoplasmic reticulum in 185 order to protect it from thermal alteration during the transit to cellular surface [25]. The relationship between HSP 47 and collagen I in the response of ovarian cancer to hyperthermia has never been explored before. Could low level of HSP47 be a marker of sensitivity to HIPEC? Proteoglycans are the second type of protein composing the ECM. Among them, versican is a 189 large chondroitine sulfate proteoglycan that belongs to the aggrecan family. Elevated versican 190 levels have been found in many malignant tumours [26]. In epithelial ovarian cancer (EOC), 191 higher levels of versican in the tumoral stroma are associated with a poor prognostic [27]. 192 Recently, in a cohort study of peritoneal carcinosis patients treated by HIPEC, high level of 193 versican was associated with a better prognosis, suggesting that the versican could be a 194 predictive marker of the response to HIPEC [28].

\section{Cellular microenvironment}

197 Cellular microenvironment is constituted of immune, stromal, endothelial, nervous system cells and organ specific cells like mesothelial cells in peritoneal metastasis or epiploon’s adipocytes, 
199

200

201

202

203

204

205

206

207

208

209

210

211

212

213

214

215

216

217

and cancer stem cells. They interact with OCC by direct cell-to-cell contact or by secreting soluble factors (chemokines).

\section{i) Mesenchymal stem cells}

Mesenchymal stem cells (MSC) are characterized by their three main attributes: stemness, multipotency and self-renewal. They can be isolated from umbilical cord, bone marrow, adipose tissue, peripheral blood, spleen and skin[29]. They can differentiate into cancer associated fibroblasts (CAF), pericytes, osteocytes, adipocytes, chondrocytes and smooth muscle cells in the tumor micro-environment (TME). Their role is to migrate toward damaged tissues and contribute to repair it by cellular support, angiogenesis and modulation of immune cell functions[30]. MSC are drawn to inflammatory environments, such as ovarian cancer, and are therefore numerous in that cancer [31,32]. In line with Paget's theory [33], comparing the cancer cell to a seed and the tissue to soil, MSC would be the fertilizer.

When MSC extracted from bone marrow are exposed to fever range hyperthermia, and cocultured with macrophage, they switched the profiles of macrophages from pro-inflammatory to anti-inflammatory, increasing secretion of interleukin 10 and lowering tumor necrosis factor alpha [34]. These changes are mediated by heat shock factor (HSF) 1's translocation into the nucleus. HSF-1 is a protein which in its stable form is located in the cytoplasm and bound to HSP 90, HSP 70 and TCP1. In the event of heat stress, HSF-1 releases these molecules whose role is to fold up heat-altered proteins. Once released, HSF-1 passes into the nucleus and activates the transcription of anti-inflammatory proteins, notably cyclo-oxygenases (COX) and prostaglandins synthases (PTGES) but also program death ligand one (PDL-1) (see Figure 2).

Finally prostaglandins cause a drop in TNF-alpha secretion and an increase in interleukin 10, orienting macrophages towards an anti-inflammatory profile [34]. In addition, PDL-1 secretion decreases T cell activity. 
224 During hyperthermia, Lis et al showed that after co-culture with MSC in transwell, OCC 225 developed a thermo-resistance at 42 degrees [35]. This relationship appears to be mediated by 226 SDF 1 and its C-X-C chemokine receptor type 4 (CXCR4) receptor whose inhibition by an anti227 CXCR4 antibody reverses the survival gain [35] (see Figure 2).

228 Concerning chemotherapy, the work of Pasquier et al.[21] showed that transwell co-culture of 229 MSC with ovarian cancer cells (OCC) decreased OCC mortality, that this MSC-OCC 230 collaboration was mediated by CCL2 and CCL5 and then in an autocrine loop OCC-OCC by 231 IL-6. These results were verified in vivo in a mouse model with an anti IL6 antibody that 232 restored sensitivity to chemotherapy. Recently Wang et al. have highlighted that MSC derived 233 CAF were able to induce an epithelial to mesenchymal transition in OCC by secreting IL-6, 234 through the JAK2/STAT3 pathway, enhancing paclitaxel resistance [36] (see Figure 2). 235 Surgical stress and heat shock increase secretion of IL-6 and IL-8 [37] and thus blood levels 236 of IL-6 are increased during HIPEC in ovarian cancer [38]. As it happens, IL-6 and IL-8 are 237 two interleukines involved in MSC's recruitment [39]. Further research should be done to 238 investigate whether hyperthermia leads to recruitment to MSC since hyperthermia induces 239 secretion of IL-6 and IL-8. It seems that MSC could participate to the unsatisfactory results of 240 HIPEC sometimes observed in ovarian cancer.

\section{ii) Immune system}

243 Ovarian cancer is an immunogenic disease and host's immunity influences the prognostic.

244 Indeed, ovarian tumours are invaded by immune cells: tumor-infiltrating lymphocytes. Many 245 intermediates of the immune system thus constitute markers of survival or response to 246 chemotherapy [40]. Fever which is by definition an increase of body temperature, is an archaic 247 defense mechanism that increases survival against infections by mobilizing the immune system. 248 Therefore, HIPEC may interfere with this complex system. 
a. Adaptative immunity

T cells

252 T cells have in common the cluster of differentiation 3 (CD 3+). According to Zhang et al. there 253 is a lymphocyte infiltration in EOC in 55\% of cases. Furthermore, the 5-year survival of patients 254 with tumor infiltrated lymphocytes (TILs) is $38 \%$ compared to $4.5 \%$ in patients whose tumors 255 do not have TILs upon pathological examination. [41]. Among T cells, CD8+ T (cytotoxic) T 256 cells and CD4+ T (helper) cells have also been confirmed as prognostic markers [42].

257 Hyperthermia leads to active recruitment of lymphocytes in veinules and lymph nodes. On the 258 lymphocyte side, this phenomenon is mediated by L-selectin and $\alpha 4 \beta 7$ integrin. On the 259 endothelial side the adhesion dependent on lymph nodes adressins (PNAd) [43] and mucosal 260 adressin cell adhesion molecule-1 (MAdCAM-1)[44]. Moreover, as we have already seen, 261 HIPEC and surgical stress leads to an increase of IL-6 [38] which is known to increase the expression of P-selectin and E-selectin in endothelial cells permitting adherence, tethering 263 rolling and finally through ICAM-1, transmigration of CD8+ T cells in the tissue [45] (see 264 Figure 2). Further research should be done to investigate whether hyperthermia increases CD8+ 265 migration in the ovarian cancer.

266 Hyperthermia enhances the cytotoxic activity of CD8+ through the expression of granzyme B, 267 perforin, and interferon $\gamma$ (IFN $\gamma$ ) [46] and nuclear HSF promotes Fas ligand expression [47]. In 268 a mice model, targeted inhibition of HSP 90 by novobiocin, suppressed TNF alpha production 269 by CD4+ cells [48]. GP96 is another thermosensitive chaperone whose activation leads to 270 priming of $\mathrm{T}$ cell response through a CD-91dependent manner [49]. Thus, it would be 271 interesting to study the ability of HIPEC to potentiate CD8+'s cytotoxicity. 
272 T cells also modulate chemoresistance in EOC. Wang et al. showed that, fibroblasts enhance

273 the efflux of cisplatin through chelation by glutathione and that CD8+ T cells were able to alter

274 this mechanism through secretion of IFN Gamma, suppressing the chemoresistance[50].

275 In total, we have shown that hyperthermia increases infiltration and cytotoxic activity of LTs.

276 However, these lymphocytes could also be involved in fibroblast-related chemoresistance.

277

278

279

280

282

283

\section{B cells}

Although T cells are extensively explored in ovarian cancer as predictive markers and for new therapeutic ways, few studies have highlighted the importance of B cells in ovarian cancer. At histology, B cells are present within the tumoral tissue to modulate the tumor microenvironment and its immune response [51]. In ovarian cancer, it seems that low density of plasma cells CD138+ [52] and high density of naïve B cells and memory B cells combined with CD8+ T cells correlated with a better prognostic [42].

HSP are involved in B cells activation. The HSF-1 complex is functional in activated B cells only, as no hHSF-1-DNA complex can be detected in naïve B cells exposed to hyperthermia [53]. HSF-1 released HSP 90 leads to proliferation of B cells and antigen presentation [54] (see Figure 2).

But B cells also act as an immunosuppressive and pro-tumoral actor. In breast cancer, B cells reduce CD8+ activity and NK cells infiltration [55] and it has been confirmed in ovarian cancer that the presence of IL-10+ B cells of naïve B-cell phenotype was associated with less cytotoxic CD8+ T cells, allowing tumour immune tolerance [56]. In this way, the maturation of B-cells provoked by the heat shock could act as an immune boost.
b. Innate immunity

\section{Macrophages}


Monocytes are part of the circulating leukocytes; they differentiate into macrophages when they leave the circulation. They are actors of innate immunity via phagocytosis but are also antigen presenters and therefore actors of acquired immunity. Tumor associated macrophages (TAM) are the most abundant immune related stromal cells in the TME. Macrophages can differentiate in two subtypes: M2 macrophage has poor antigen-presenting capacity, prevents T-cell activation, contributes to suppressing dendritic cell (DC) functions, as well as enhances angiogenesis and metastasis. M1 macrophages are the opposite [57].

When TAMs are exposed to cisplatin, they increase their production of the chemokine CCL20 that activates its receptor CCR6 in OCC triggering EMT[58]. Facing hyperthermia, macrophages activate the HSF-1 complex. Nuclear HSF-1 promotes IL-10 and its receptor transcription in macrophages[59]. IL-10 inhibits production of many cytokines, notably IL-1, IL-6, TNF and PAF that are crucial to its anti-inflammatory activities and its amplification through different pathways (see Figure 2). Macrophage’s functions are increased up to $40^{\circ}$ and then inhibited over $41^{\circ}$ in mice [60]. Furthermore, as we have seen previously, hyperthermia leads to vasodilatation which reduces tissue hypoxia. However, when macrophages are subjected to hypoxia, they release exosomes that deliver miR-223 to elicit a chemoresistance phenotype in EOC. HIPEC would prevent this event.

Overall, HIPEC via macrophages could have an ambivalent role: on the one hand, hyperthermia it reduces inflammatory activity via IL10 and on the other, it prevents the occurrence of chemoresistance.

\section{Dendritic cells}

Dendritic cells (DC) are highly specialized antigen presentating cells. In this manner they can recognize tumor associated antigens (TAA) and induce specific T-cell effectors. Presence of 
321 immature DC at histology is associated with poor outcome [40]. Enhancement of DC activity

322 or its presentation of TAA has been in the center of many trials[61].

323 Heat stressed EOC exosomes are able to induce dendritic cell (DC) maturation. Compared to 324 non-heat stressed tumor exosomes, they contain more HSP 70, more MHC-1 and are more 325 effective for inducing differentiation of activated monocytes into mature DC [62]. These DCs 326 can induce the activation of CD4+ and CD8+ T cells to obtain an antitumor immune effect [62].

327 Similarly, in patients with colorectal cancer treated by local hyperthermia, exosomes derived 328 from tumor cells are able to stimulate dendritic cells to secrete more IL-6 promoting the 329 differentiation of Th 17 regulatory T-lymphocytes; resulting in an anti-tumor effect [63]. HSP 33070 secreted by the cancer cell after chemical[64] or heat exposure [65] acts like a DC antigen 331 enhancing immunity against the tumor through Toll Like Receptor (TLR) 4. HSP 90 also 332 accelerates DC maturation (see Figure 2) [66].

333 Thus, HIPEC certainly enhances the immune activity of dendritic cells.

\section{Natural Killer cells}

336 Natural killer (NK) cells are cytotoxic cells that have the capacity of elicit inflammation through 337 antigen-independent pathways and detect loss of HLA as a signal for activation. Its presence in 338 ovarian cancer microenvironment is associated with poor prognosis [67].

339 Although debated, it seems that hyperthermia promotes the cytotoxicity of NK cells. HSP 70 340 in cancer cells increases natural killer lectin-like receptor gene 2D (NKG2D) ligand-receptors 341 [68]. HSP 70 also stimulates NK cells through expression of NKG2D, CD56 and CD94 (see 342 Figure 2) [69]. On the contrary, Koga et al. exposed mice to whole body hyperthermia at 42 343 degrees and showed less expression perforin and granzyme B but identical expression of TNF 344 cytokines [70].

345 Further studies are needed to establish the exact impact of HIPEC on NK cells. 
iii) Endothelial cells and microvascular tumoral network

Endothelial cells participate in tumor progression by promoting neo-angiogenesis. Anti-

349 angiogenic therapies should therefore increase overall survival. However, these treatments are 350 disappointing given that bevacizumab does not improve survival in ovarian cancer [71]. By 351 blocking neo-angiogenesis, the tumor evolves in a hypoxic environment and activates 352 alternative pathways [72].

When Sun et al. explored the variation of hypoxia after hyperthermia in various tumor,

354 they observed that even if the main effect was increasing the oxygenation of tumoral tissue 355 through vasodilatation, the regions with the highest hypoxia (ie lowest vascularization) indeed suffered from increased hypoxia after hyperthermia [73]. Therefore, in these areas, endothelial cells secrete angiocrines particles promoting neo-angiogenesis after hyperthermia [74,75] . This process then creates vascular niches for tumor progression [76].

Moreover, EOC is able to transform the surrounding endothelium in an angiocrine endothelium [77]. One of the ways for EOC to influence the epithelium is by secreting HSP90.

361 Secretion of HSP $90 \alpha$ (one of the two the cytosolic forms) is heat inducible [78]. However it 362 has been shown that HSP90 is increasing expression of vascular endothelial growth factors 363 (VEGF) receptors on human endothelial and lymphatic cells (see Figure 2); and thus the possibility of decreasing this expression with an HSP 90 inhibitor [79]. In this manner, these data could represent arguments against HIPEC.

It seems mandatory to remind that endothelial cells are playing an essential role in 367 resistance to chemotherapy. For instance, Hoarau-véchot et al, demonstrated that OCC were 368 able to activate endothelial cells through the phosphatidylinositol 3-kinase/Akt pathway [80], 369 when cocultured with Akt-activated endothelial cells, OCCs developed chemoresistance 370 through Notch pathway. Therefore, even if the role of endothelial cells in hyperthermia needs 
371 to be investigate further, it is clear that they have a real role in resistance to chemotherapy and

372 they shouldn't be neglected.

373

374

375

376

377

378

379

380 survival within the fat. exposed to HIPEC. facilitate FFA release[86].

\section{iv) Adipose stromal cells}

The peritoneal cavity contains adipose tissue. The large epiploon, which is a frequent site of metastasis, is routinely removed during debulking surgery. The peritoneum is bordered on its outer surface by adipose tissue and the mesos, the nourishing blades of the digestive tract, is mainly made up of adipose tissue. During debulking surgery, after multiple manipulations of the omentum before removal, and extended peritonectomy, adipose tissue and adipocytes are

In OCC, coculture with adipocytes increases chemoresistance to cisplatin and paclitaxel through the PI3K/Akt signalling pathway, arachidonic acid secretion [81], and miR21 transfer to OCC[82]. There are actually no data on the effect of HIPEC on adipose tissue.

Fever range heat exposure induces lipolysis in rat's adipocytes [83] meaning a release of free fatty acid (FFA) locally and in blood stream. However, these FFA constitute an energy reserve, contributing to tumour growth and metastasis [84].

Moreover, adipose tissue responds differently to heat depending on its location [83]. Thus, more metabolically active fat as retroperitoneal fat express more HSP after heat exposure at fever range than subcutaneal fat $[83,85]$. Omental fat spontaneously expresses more HSP 70 , and HSP 90 [85] and cancer associated adipocytes transfers HSP 70 into their lipid droplets to

Therefore, extended peritonectomy, bowel and omental manipulations could expose adipocyte to HIPEC and EOC to adipocytes and trigger a cellular alliance resulting in EOC 
397 The intercellular mechanisms involved in the exposure of tumour microenvironment to HIPEC 398 are various. Even if it seems that the combination of hyperthermia and chemotherapy 399 constitutes an immune boost, it would seem that mesenchymal cells but also its endothelial and 400 adipocyte relatives could actually protect the remaining cells and explain the peritoneal 401 recurrences despite radical surgery supplemented by HIPEC procedure.

402 The tumour microenvironment constitutes a variable in tumour identity and its characterization 403 could lead to i) better select patients beneficiating from HIPEC such as a targeted therapy. For

404 405 406

407 408 409 example, high concentration of versican, a high density of T cells or low labelling in HSP 90, could constitute enhanced indications for HIPEC. ii) to use targeted therapy in addition to HIPEC: blocking resistance mechanisms involved in HIPEC, such as the use of anti-IL-6, anti CXCR-4 or anti HSP-90 during the procedure, may also be considered.

With this in mind, we are currently conducting a translational study on primary lines of advanced epithelial cancers taken during exploratory laparoscopy or debulking, in order to determine a predictive profile of response to HIPEC but also the role of different players in the microenvironment in resistance to HIPEC. Nevertheless, the study of the role of the microenvironment in the resistance mechanisms of ovarian cancer remains a topical issue of great interest.

\section{Conflicts of interest:}

This research did not receive any specific grant from funding agencies in the public, commercial, or not-for-profit sectors.

The authors have no conflict of interest to declare in connection with this work. Authors' contributions:

AC and LB carried out the bibliographical research and writing.

CT and JP did the formatting and corrections. 
None

\section{REFERENCES}

[1] van Driel WJ, Koole SN, Sikorska K, Schagen van Leeuwen JH, Schreuder HWR, Hermans RHM, et al. Hyperthermic Intraperitoneal Chemotherapy in Ovarian Cancer. N Engl J Med 2018;378:230-40. https://doi.org/10.1056/NEJMoa1708618.

[2] Zivanovic O, Chi DS, Filippova O, Randall LM, Bristow RE, O'Cearbhaill RE. It's time to warm up to hyperthermic intraperitoneal chemotherapy for patients with ovarian cancer. Gynecologic Oncology 2018;151:555-61. https://doi.org/10.1016/j.ygyno.2018.09.007.

[3] Box C, Rogers SJ, Mendiola M, Eccles SA. Tumour-microenvironmental interactions: paths to progression and targets for treatment. Seminars in Cancer Biology 2010;20:128-38. https://doi.org/10.1016/j.semcancer.2010.06.004.

[4] Roma-Rodrigues C, Mendes R, Baptista P, Fernandes A. Targeting Tumor Microenvironment for Cancer Therapy. International Journal of Molecular Sciences 2019;20:840. https://doi.org/10.3390/ijms20040840.

[5] Lis R, Touboul C, Mirshahi P, Ali F, Mathew S, Nolan DJ, et al. Tumor associated mesenchymal stem cells protects ovarian cancer cells from hyperthermia through CXCL12. Int J Cancer 2011;128:715-25. https://doi.org/10.1002/ijc.25619.

[6] Sakaguchi Y, Stephens LC, Makino M, Kaneko T, Strebel FR, Danhauser LL, et al. Apoptosis in tumors and normal tissues induced by whole body hyperthermia in rats. Cancer Res 1995;55:5459-64.

[7] Oleson JR, Samulski TV, Leopold KA, Clegg ST, Dewhirst MW, Dodge RK, et al. Sensitivity of hyperthermia trial outcomes to temperature and time: Implications for thermal goals of treatment. International Journal of Radiation Oncology*Biology*Physics 1993;25:289-97. https://doi.org/10.1016/03603016(93)90351-U.

[8] Lee YJ, Lee JY, Cho MS, Nam EJ, Kim SW, Kim S, et al. Incorporation of paclitaxel-based hyperthermic intraperitoneal chemotherapy in patients with advanced-stage ovarian cancer treated with neoadjuvant chemotherapy followed by interval debulking surgery: a protocol-based pilot study. J Gynecol Oncol 2019;30:e3. https://doi.org/10.3802/jgo.2019.30.e3.

[9] Song CW, Choi IB, Nah BS, Sahu SK, Osborn JL. Microvasculature and Perfusion in Normal Tissues and Tumors. In: Seegenschmiedt MH, Fessenden P, Vernon CC, editors. Thermoradiotherapy and Thermochemotherapy, Berlin, Heidelberg: Springer Berlin Heidelberg; 1995, p. 139-56. https://doi.org/10.1007/978-3-642-57858-8_7.

[10] L-G LFF. Pathological Effects of Hyperthermia in Normal Tissues 1984;44:11.

[11] Wust P, Hildebrandt B, Sreenivasa G, Rau B, Gellermann J, Riess H, et al. Hyperthermia in combined treatment of cancer. Lancet Oncol 2002;3:487-97. 
[12] Armstrong DK, Bundy B, Wenzel L, Huang HQ, Baergen R, Lele S, et al. Intraperitoneal cisplatin and paclitaxel in ovarian cancer. N Engl J Med 2006;354:34-43. https://doi.org/10.1056/NEJMoa052985.

[13] Teefey P, Zgheib NB, Apte SM, Gonzalez-Bosquet J, Judson PL, Roberts WS, et al. Factors associated with improved toxicity and tolerability of intraperitoneal chemotherapy in advanced-stage epithelial ovarian cancers. American Journal of Obstetrics and Gynecology 2013;208:501.e1-501.e7. https://doi.org/10.1016/j.ajog.2013.03.012.

[14] Oaknin A, Roda D, González-Martín A, Chiva L, García-Donas J, de Juan A, et al. Feasibility of a Modified Outpatient Regimen of Intravenous/Intraperitoneal Chemotherapy in Optimally Debulked Stage III Ovarian Cancer Patients: A GEICO Study. International Journal of Gynecological Cancer 2011;21:1048-55. https://doi.org/10.1097/IGC.0b013e31821ee777.

[15] Walker JL, Brady MF, Wenzel L, Fleming GF, Huang HQ, DiSilvestro PA, et al. Randomized Trial of Intravenous Versus Intraperitoneal Chemotherapy Plus Bevacizumab in Advanced Ovarian Carcinoma: An NRG Oncology/Gynecologic Oncology Group Study. JCO 2019;37:1380-90. https://doi.org/10.1200/JCO.18.01568.

[16] de Lima Vazquez V, Stuart OA, Mohamed F, Sugarbaker PH. Extent of parietal peritonectomy does not change intraperitoneal chemotherapy pharmacokinetics. Cancer Chemother Pharmacol 2003;52:108-12. https://doi.org/10.1007/s00280-0030626-8.

[17] Xu M, Alberts DavidS. Potentiation of platinum analogue cytotoxicity by hyperthermia. Cancer Chemother Pharmacol 1988;21. https://doi.org/10.1007/BF00262768.

[18] Miyagi Y, Fujiwara K, Kigawa J, Itamochi H, Nagao S, Aotani E, et al. Intraperitoneal carboplatin infusion may be a pharmacologically more reasonable route than intravenous administration as a systemic chemotherapy. A comparative pharmacokinetic analysis of platinum using a new mathematical model after intraperitoneal vs. intravenous infusion of carboplatin-A Sankai Gynecology Study Group (SGSG) study. Gynecologic Oncology 2005;99:591-6. https://doi.org/10.1016/j.ygyno.2005.06.055.

[19] Los G, Verdegaal EM, Mutsaers PH, McVie JG. Penetration of carboplatin and cisplatin into rat peritoneal tumor nodules after intraperitoneal chemotherapy. Cancer Chemother Pharmacol 1991;28:159-65. https://doi.org/10.1007/bf00685503.

[20] Morales-Soriano R, Esteve-Pérez N, Segura-Sampedro JJ, Cascales-Campos P, Barrios $\mathrm{P}$, Alonso-Gómez J, et al. Current practice in cytoreductive surgery and HIPEC for metastatic peritoneal disease: Spanish multicentric survey. European Journal of Surgical Oncology 2018;44:228-36. https://doi.org/10.1016/j.ejso.2017.11.012.

[21] Pasquier J, Gosset M, Geyl C, Hoarau-Véchot J, Chevrot A, Pocard M, et al. CCL2/CCL5 secreted by the stroma induce IL-6/PYK2 dependent chemoresistance in ovarian cancer. Molecular Cancer 2018;17:47. https://doi.org/10.1186/s12943-018-0787-z.

[22] Mecham RP. Overview of Extracellular Matrix. Current Protocols in Cell Biology 2012;57. https://doi.org/10.1002/0471143030.cb1001s57.

[23] Hynes RO, Naba A. Overview of the Matrisome--An Inventory of Extracellular Matrix Constituents and Functions. Cold Spring Harbor Perspectives in Biology 2012;4:a004903-a004903. https://doi.org/10.1101/cshperspect.a004903. 
[24] FLATE E, STALVEY JRD. Motility of select ovarian cancer cell lines: Effect of extracellular matrix proteins and the involvement of PAK2. Int J Oncol 2014;45:140111. https://doi.org/10.3892/ijo.2014.2553.

[25] Verrico AK, Moore JV. Expression of the collagen-related heat shock protein HSP47 in fibroblasts treated with hyperthermia or photodynamic therapy. Br J Cancer 1997;76:719-24.

[26] Tsara ME, Theocharis AD, Theocharis DA. Compositional and structural alterations of proteoglycans in human rectum carcinoma with special reference to versican and decorin. Anticancer Res 2002;22:2893-8.

[27] Voutilainen K, Anttila M, Sillanpää S, Tammi R, Tammi M, Saarikoski S, et al. Versican in epithelial ovarian cancer: Relation to hyaluronan, clinicopathologic factors and prognosis. International Journal of Cancer 2003;107:359-64. https://doi.org/10.1002/ijc.11423.

[28] Sluiter NR, de Cuba EMV, Kwakman R, Meijerink WJHJ, Delis-van Diemen PM, Coupé $\mathrm{VMH}$, et al. Versican and vascular endothelial growth factor expression levels in peritoneal metastases from colorectal cancer are associated with survival after cytoreductive surgery and hyperthermic intraperitoneal chemotherapy. Clin Exp Metastasis 2016;33:297-307. https://doi.org/10.1007/s10585-016-9779-9.

[29] Bianco P, Robey PG, Simmons PJ. Mesenchymal stem cells: revisiting history, concepts, and assays. Cell Stem Cell 2008;2:313-9. https://doi.org/10.1016/j.stem.2008.03.002.

[30] Nombela-Arrieta C, Ritz J, Silberstein LE. The elusive nature and function of mesenchymal stem cells. Nat Rev Mol Cell Biol 2011;12:126-31. https://doi.org/10.1038/nrm3049.

[31] Lee MJ, Jeon ES, Lee JS, Cho M, Suh D-S, Chang CL, et al. Lysophosphatidic acid in malignant ascites stimulates migration of human mesenchymal stem cells. I Cell Biochem 2008;104:499-510. https://doi.org/10.1002/jcb.21641.

[32] Touboul C, Vidal F, Pasquier J, Lis R, Rafii A. Role of mesenchymal cells in the natural history of ovarian cancer: a review. J Transl Med 2014;12:1-17. https://doi.org/10.1186/s12967-014-0271-5.

[33] Paget S. The distribution of secondary growths in cancer of the breast. 1889. Cancer Metastasis Rev 1989;8:98-101.

[34] Mcclain-Caldwell I, Vitale-Cross L, Mayer B, Krepuska M, Boyajian M, Myneni V, et al. Immunogenic potential of human bone marrow mesenchymal stromal cells is enhanced by hyperthermia. Cytotherapy 2018;20:1437-44. https://doi.org/10.1016/j.jcyt.2018.10.002.

[35] Lis R, Touboul C, Mirshahi P, Ali F, Mathew S, Nolan DJ, et al. Tumor associated mesenchymal stem cells protects ovarian cancer cells from hyperthermia through CXCL12. International Journal of Cancer 2011;128:715-25. https://doi.org/10.1002/ijc.25619.

[36] Wang L, Zhang F, Cui J-Y, Chen L, Chen Y-T, Liu B-W. CAFs enhance paclitaxel resistance by inducing EMT through the IL-6/JAK2/STAT3 pathway. Oncology Reports 2018;39:2081-90. https://doi.org/10.3892/or.2018.6311.

[37] Pasquier J, Vidal F, Hoarau-Véchot J, Bonneau C, Daraï E, Touboul C, et al. Surgical peritoneal stress creates a pro-metastatic niche promoting resistance to apoptosis via IL-8. Journal of Translational Medicine 2018;16:271. https://doi.org/10.1186/s12967018-1643-z. 
[38] Coccolini F, Corbella D, Finazzi P, Brambillasca P, Benigni A, Prussiani V, et al. Time course of cytokines, hemodynamic and metabolic parameters during hyperthermic intraperitoneal chemotherapy. Minerva Anestesiol 2016;82:310-9.

[39] Bayo J, Real A, Fiore EJ, Malvicini M, Sganga L, Bolontrade M, et al. IL-8, GRO and MCP1 produced by hepatocellular carcinoma microenvironment determine the migratory capacity of human bone marrow-derived mesenchymal stromal cells without affecting tumor aggressiveness. Oncotarget 2016;8:80235-48. https://doi.org/10.18632/oncotarget.10288.

[40] Li J, Wang J, Chen R, Bai Y, Lu X. The prognostic value of tumor-infiltrating $T$ lymphocytes in ovarian cancer. Oncotarget 2017;8:15621-31. https://doi.org/10.18632/oncotarget.14919.

[41] Zhang L, Conejo-Garcia JR, Katsaros D, Gimotty PA, Massobrio M, Regnani G, et al. Intratumoral T Cells, Recurrence, and Survival in Epithelial Ovarian Cancer. Http://DxDoiOrg/101056/NEJMoa020177 2009. https://doi.org/10.1056/NEJMoa020177.

[42] Santoiemma PP, Powell DJ. Tumor infiltrating lymphocytes in ovarian cancer. Cancer Biology \& Therapy 2015;16:807-20. https://doi.org/10.1080/15384047.2015.1040960.

[43] Streeter PR, Berg EL, Rouse BTN, Bargatze RF, Butcher EC. A tissue-specific endothelial cell molecule involved in lymphocyte homing. Nature 1988;331:41-6. https://doi.org/10.1038/331041a0.

[44] Nakache M, Berg EL, Streeter PR, Butcher EC. The mucosal vascular addressin is a tissue-specific endothelial cell adhesion molecule for circulating lymphocytes. Nature 1989;337:179-81. https://doi.org/10.1038/337179a0.

[45] Fisher DT, Chen Q, Skitzki JJ, Muhitch JB, Zhou L, Appenheimer MM, et al. IL-6 transsignaling licenses mouse and human tumor microvascular gateways for trafficking of cytotoxic T cells. J Clin Invest 2011;121:3846-59. https://doi.org/10.1172/JCl44952.

[46] Takahashi A, Torigoe T, Tamura Y, Kanaseki T, Tsukahara T, Sasaki Y, et al. Heat shock enhances the expression of cytotoxic granule proteins and augments the activities of tumor-associated antigen-specific cytotoxic T lymphocytes. Cell Stress Chaperones 2012;17:757-63. https://doi.org/10.1007/s12192-012-0348-0.

[47] Bouchier-Hayes L, McBride S, van Geelen CM, Nance S, Lewis LK, Pinkoski MJ, et al. Fas ligand gene expression is directly regulated by stress-inducible heat shock transcription factor-1. Cell Death Differ 2010;17:1034-46. https://doi.org/10.1038/cdd.2010.4.

[48] Collins CB, Strassheim D, Aherne CM, Yeckes AR, Jedlicka P, de Zoeten EF. Targeted inhibition of heat shock protein 90 suppresses tumor necrosis factor- $\alpha$ and ameliorates murine intestinal inflammation. Inflamm Bowel Dis 2014;20:685-94. https://doi.org/10.1097/01.MIB.0000442839.28664.75.

[49] Pawaria S, Binder RJ. CD91-dependent programming of T-helper cell responses following heat shock protein immunization. Nat Commun 2011;2:521. https://doi.org/10.1038/ncomms1524.

[50] Wang W, Kryczek I, Dostál L, Lin H, Tan L, Zhao L, et al. Effector T Cells Abrogate Stroma-Mediated Chemoresistance in Ovarian Cancer. Cell 2016;165:1092-105. https://doi.org/10.1016/j.cell.2016.04.009.

[51] Sarvaria A, Madrigal JA, Saudemont A. B cell regulation in cancer and anti-tumor immunity. Cell Mol Immunol 2017;14:662-74. https://doi.org/10.1038/cmi.2017.35. 
[52] Lundgren S, Berntsson J, Nodin B, Micke P, Jirström K. Prognostic impact of tumourassociated B cells and plasma cells in epithelial ovarian cancer. J Ovarian Res 2016;9:21. https://doi.org/10.1186/s13048-016-0232-0.

[53] Hardy L, Goodman M, Vasquez A, Chauhan D, Anderson KC, Voellmy R, et al. Activation signals regulate heat shock transcription factor 1 in human $B$ lymphocytes. Journal of Cellular Physiology 1997;170:235-40. https://doi.org/10.1002/(SICI)10974652(199703)170:3<235::AID-JCP3>3.0.CO;2-P.

[54] Houlihan JL, Metzler JJ, Blum JS. HSP90alpha and HSP90beta isoforms selectively modulate MHC class II antigen presentation in B cells. J Immunol 2009;182:7451-8. https://doi.org/10.4049/jimmunol.0804296.

[55] Zhang Y, Morgan R, Chen C, Cai Y, Clark E, Khan WN, et al. Mammary-tumor-educated $B$ cells acquire LAP/TGF- $\beta$ and PD-L1 expression and suppress anti-tumor immune responses. Int Immunol 2016;28:423-33. https://doi.org/10.1093/intimm/dxw007.

[56] Wei X, Jin Y, Tian Y, Zhang H, Wu J, Lu W, et al. Regulatory B cells contribute to the impaired antitumor immunity in ovarian cancer patients. Tumor Biol 2016;37:6581-8. https://doi.org/10.1007/s13277-015-4538-0.

[57] Condeelis J, Pollard JW. Macrophages: Obligate Partners for Tumor Cell Migration, Invasion, and Metastasis. Cell 2006;124:263-6. https://doi.org/10.1016/j.cell.2006.01.007.

[58] Liu W, Wang W, Wang X, Xu C, Zhang N, Di W. Cisplatin-stimulated macrophages promote ovarian cancer migration via the CCL20-CCR6 axis. Cancer Letters 2020;472:59-69. https://doi.org/10.1016/j.canlet.2019.12.024.

[59] Zhang $H$, Zhang L, Yu F, Liu Y, Liang $Q$, Deng G, et al. HSF1 is a transcriptional activator of IL-10 gene expression in RAW264.7 macrophages. Inflammation 2012;35:1558-66. https://doi.org/10.1007/s10753-012-9471-4.

[60] Yoshioka H, Koga S, Maeta M, Shimizu N, Hamazoe R, Murakami A. The influence of hyperthermia in vitro on the functions of peritoneal macrophages in mice. Jpn J Surg 1990;20:119-22.

[61] Drakes ML, Stiff PJ. Understanding dendritic cell immunotherapy in ovarian cancer. Expert Review of Anticancer Therapy 2016;16:643-52. https://doi.org/10.1080/14737140.2016.1178576.

[62] Flores I, Hevia D, Tittarelli A, Soto D, Rojas-Sepúlveda D, Pereda C, et al. Dendritic Cells Loaded with Heat Shock-Conditioned Ovarian Epithelial Carcinoma Cell Lysates Elicit T Cell-Dependent Antitumor Immune Responses In Vitro. J Immunol Res 2019;2019. https://doi.org/10.1155/2019/9631515.

[63] Guo D, Chen Y, Wang S, Yu L, Shen Y, Zhong H, et al. Exosomes from heat-stressed tumour cells inhibit tumour growth by converting regulatory T cells to Th17 cells via IL6. Immunology 2018;154:132-43. https://doi.org/10.1111/imm.12874.

[64] Fang $H$, Ang $B, X u X$, Huang $X, W u Y$, Sun $Y$, et al. TLR4 is essential for dendritic cell activation and anti-tumor T-cell response enhancement by DAMPs released from chemically stressed cancer cells. Cell Mol Immunol 2014;11:150-9. https://doi.org/10.1038/cmi.2013.59.

[65] Meng F-D, Sui C-G, Tian X, Li Y, Yang C-M, Ma P, et al. Heat-shock protein 70 as a tumor antigen for in vitro dendritic cell pulsing in renal cell carcinoma cases. Asian Pac J Cancer Prev 2014;15:8947-50. https://doi.org/10.7314/apjcp.2014.15.20.8947. 
[66] Basu S, Srivastava PK. Fever-like temperature induces maturation of dendritic cells through induction of hsp90. Int Immunol 2003;15:1053-61. https://doi.org/10.1093/intimm/dxg104.

[67] Dong HP, Elstrand MB, Holth A, Silins I, Berner A, Trope CG, et al. NK- and B-Cell Infiltration Correlates With Worse Outcome in Metastatic Ovarian Carcinoma. Am J Clin Pathol 2006;125:451-8. https://doi.org/10.1309/15B66DQMFYYM78CJ.

[68] Kim J-Y, Son Y-O, Park S-W, Bae J-H, Chung JS, Kim HH, et al. Increase of NKG2D ligands and sensitivity to NK cell-mediated cytotoxicity of tumor cells by heat shock and ionizing radiation. Exp Mol Med 2006;38:474-84. https://doi.org/10.1038/emm.2006.56.

[69] Gross C, Schmidt-Wolf IGH, Nagaraj S, Gastpar R, Ellwart J, Kunz-Schughart LA, et al. Heat shock protein 70-reactivity is associated with increased cell surface density of CD94/CD56 on primary natural killer cells. Cell Stress Chaperones 2003;8:348-60. https://doi.org/10.1379/1466-1268(2003)008<0348:hspria>2.0.co;2.

[70] Koga T, Harada H, Shi TS, Okada S, Suico MA, Shuto T, et al. Hyperthermia suppresses the cytotoxicity of NK cells via down-regulation of perforin/granzyme B expression. Biochem Biophys Res Commun 2005;337:1319-23. https://doi.org/10.1016/j.bbrc.2005.09.184.

[71] Tewari KS, Burger RA, Enserro D, Norquist BM, Swisher EM, Brady MF, et al. Final Overall Survival of a Randomized Trial of Bevacizumab for Primary Treatment of Ovarian Cancer. J Clin Oncol 2019;37:2317-28. https://doi.org/10.1200/JCO.19.01009.

[72] Pàez-Ribes M, Allen E, Hudock J, Takeda T, Okuyama H, Viñals F, et al. Antiangiogenic therapy elicits malignant progression of tumors to increased local invasion and distant metastasis. Cancer Cell 2009;15:220-31. https://doi.org/10.1016/j.ccr.2009.01.027.

[73] Sun X, Xing L, Ling CC, Li GC. The effect of mild temperature hyperthermia on tumour hypoxia and blood perfusion: relevance for radiotherapy, vascular targeting and imaging. International Journal of Hyperthermia 2010;26:224-31. https://doi.org/10.3109/02656730903479855.

[74] Butler JM, Kobayashi H, Rafii S. Instructive role of the vascular niche in promoting tumour growth and tissue repair by angiocrine factors. Nat Rev Cancer 2010;10:13846. https://doi.org/10.1038/nrc2791.

[75] Hoarau-Véchot J, Touboul C, Halabi N, Blot-Dupin M, Lis R, Khalil CA, et al. Aktactivated endothelium promotes ovarian cancer proliferation through notch activation. J Transl Med 2019;17:1-11. https://doi.org/10.1186/s12967-019-1942-z.

[76] Ghiabi P, Jiang J, Pasquier J, Maleki M, Abu-Kaoud N, Rafii S, et al. Endothelial cells provide a notch-dependent pro-tumoral niche for enhancing breast cancer survival, stemness and pro-metastatic properties. PLOS ONE 2014;9:e112424. https://doi.org/10.1371/journal.pone.0112424.

[77] Pasquier J, Ghiabi P, Chouchane L, Razzouk K, Rafii S, Rafii A. Angiocrine endothelium: from physiology to cancer. Journal of Translational Medicine 2020;18. https://doi.org/10.1186/s12967-020-02244-9.

[78] Sreedhar AS, Kalmár E, Csermely P, Shen Y-F. Hsp90 isoforms: functions, expression and clinical importance. FEBS Lett 2004;562:11-5. https://doi.org/10.1016/s00145793(04)00229-7.

[79] Nagengast WB, Korte MA de, Munnink THO, Timmer-Bosscha H, Dunnen WF den, Hollema H, et al. 89Zr-Bevacizumab PET of Early Antiangiogenic Tumor Response to 
702

703

704

705

706

707

708

709

710

711

712

713

714

715

716

717

718

719

720

721

722

723

724

725

726

Treatment with HSP90 Inhibitor NVP-AUY922. J Nucl Med 2010;51:761-7. https://doi.org/10.2967/jnumed.109.071043.

[80] Bussolati B, Assenzio B, Deregibus MC, Camussi G. The proangiogenic phenotype of human tumor-derived endothelial cells depends on thrombospondin-1 downregulation via phosphatidylinositol 3-kinase/Akt pathway. J Mol Med 2006;84:852-63. https://doi.org/10.1007/s00109-006-0075-z.

[81] Yang J, Zaman MM, Vlasakov I, Roy R, Huang L, Martin CR, et al. Adipocytes promote ovarian cancer chemoresistance. Sci Rep 2019;9:1-12. https://doi.org/10.1038/s41598-019-49649-1.

[82] Yeung CLA, Co N-N, Tsuruga T, Yeung T-L, Kwan S-Y, Leung CS, et al. Exosomal transfer of stroma-derived miR21 confers paclitaxel resistance in ovarian cancer cells through targeting APAF1. Nat Commun 2016;7:1-14. https://doi.org/10.1038/ncomms11150.

[83] Rogers RS, Beaudoin M-S, Wheatley JL, Wright DC, Geiger PC. Heat shock proteins: in vivo heat treatments reveal adipose tissue depot-specific effects. J Appl Physiol (1985) 2015;118:98-106. https://doi.org/10.1152/japplphysiol.00286.2014.

[84] Yan F, Shen N, Pang JX, Zhang YW, Rao EY, Bode AM, et al. Fatty acid-binding protein FABP4 mechanistically links obesity with aggressive AML by enhancing aberrant DNA methylation in AML cells. Leukemia 2017;31:1434-42. https://doi.org/10.1038/leu.2016.349.

[85] Pérez-Pérez R, Ortega-Delgado FJ, García-Santos E, López JA, Camafeita E, Ricart W, et al. Differential proteomics of omental and subcutaneous adipose tissue reflects their unalike biochemical and metabolic properties. J Proteome Res 2009;8:1682-93. https://doi.org/10.1021/pr800942k.

[86] Jiang H, He J, Pu S, Tang C, Xu G. Heat shock protein 70 is translocated to lipid droplets in rat adipocytes upon heat stimulation. Biochimica et Biophysica Acta (BBA) Molecular and Cell Biology of Lipids 2007;1771:66-74. https://doi.org/10.1016/j.bbalip.2006.10.004.

\section{Legends:}

Table 1 : Table 1: HIPEC trials through the last 10 years.

Figure 1: HIPEC open technique : Coliseum.

Figure 2: Biocellular mechanisms at work in the ovarian tumor microenvironment during

HIPEC. 


\section{OPEN TECHNIQUE : COLISEUM}
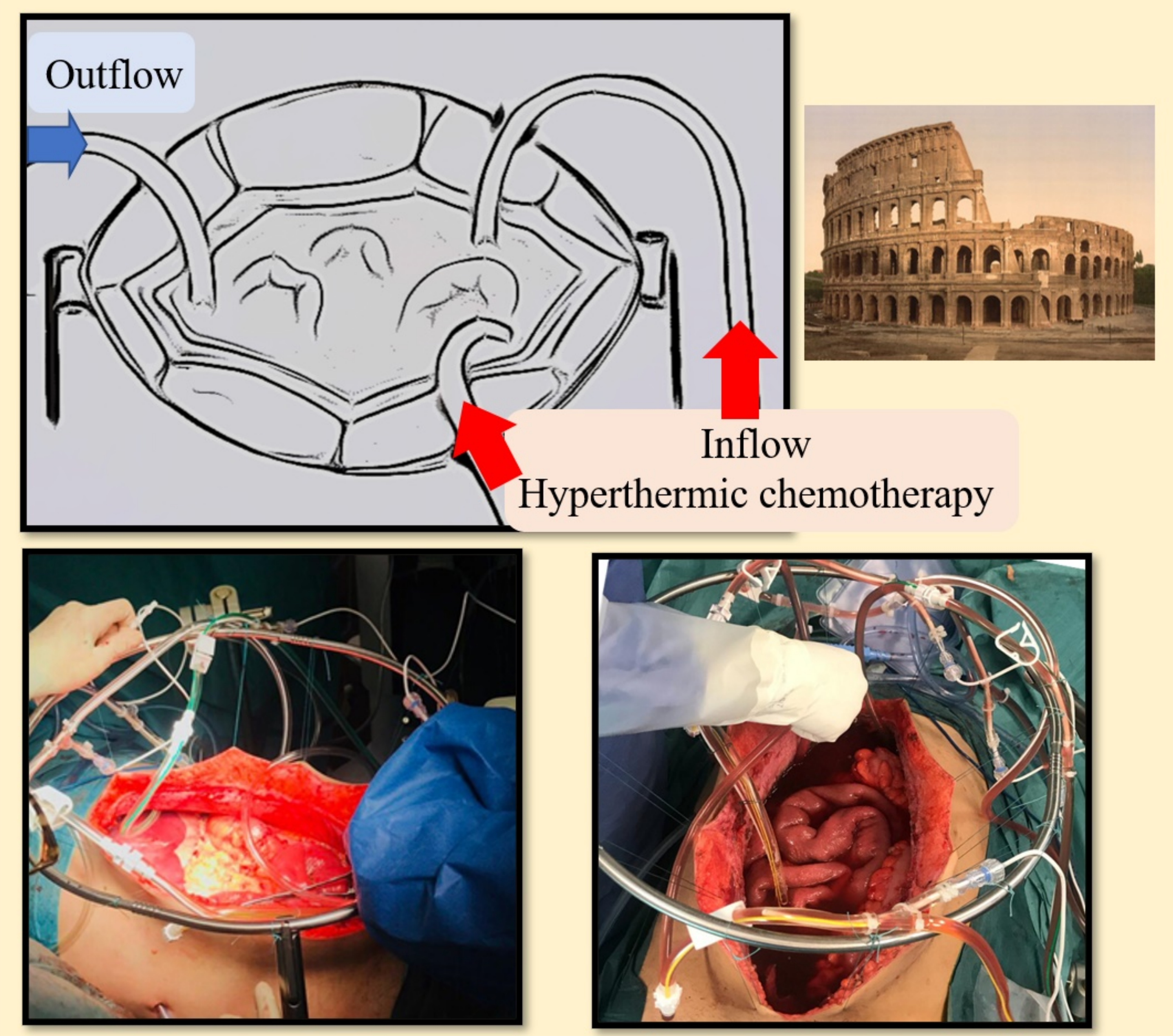

\section{CLOSED TECHNIQUE}

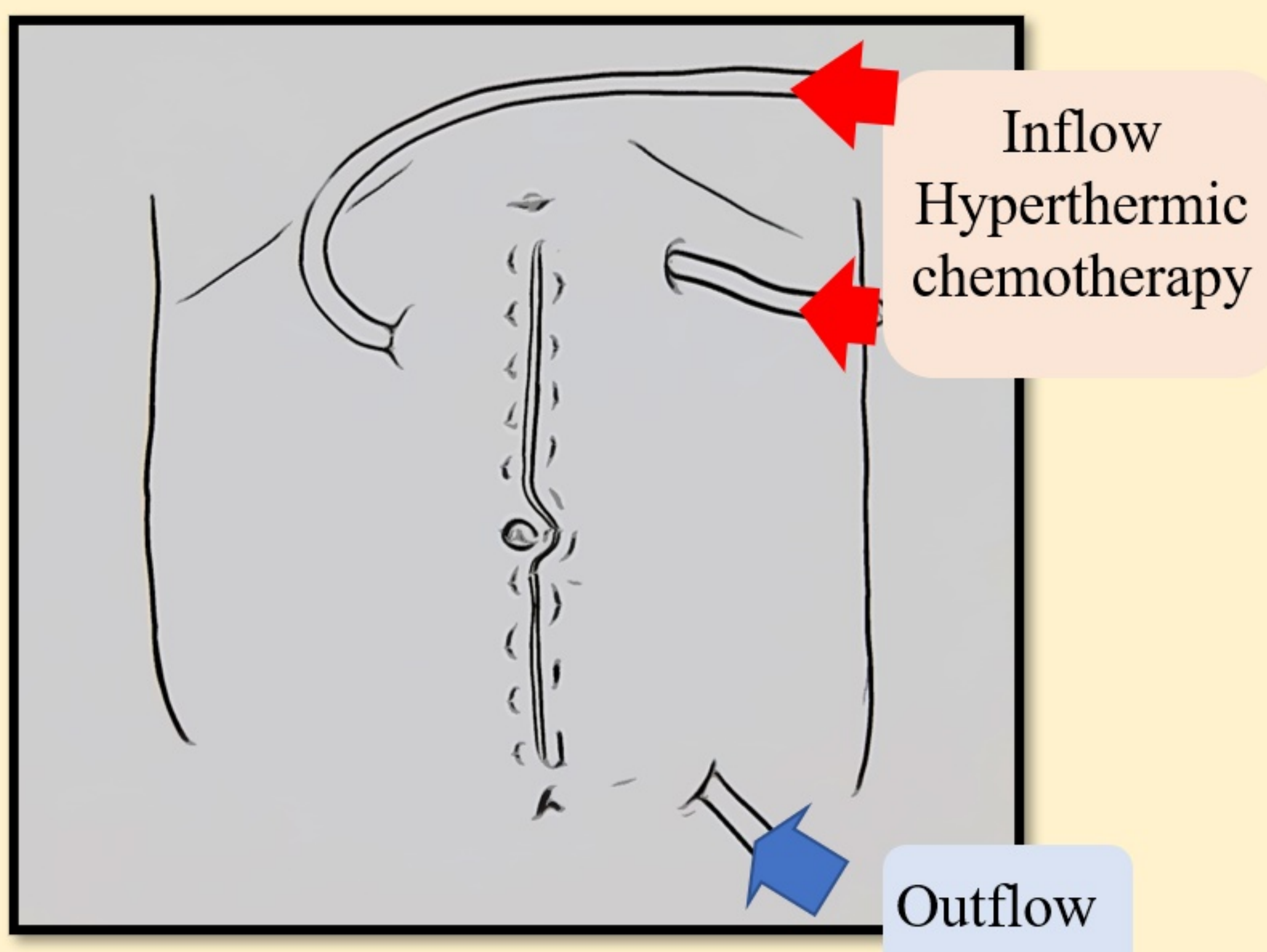

The OPEN technique is the most commonly used 
